\title{
Effect of oxidoreduction potential and of gas bubbling on rheological properties and microstructure of acid skim milk gels acidified with glucono- $\delta$-lactone
}

\author{
F. Martin, ${ }^{*}$ N. Cayot,$\dagger^{1}$ A. Marin, $\ddagger$ L. Journaux, $\ddagger$ P. Cayot, $\S$ P. Gervais, ${ }^{*}$ and R. Cachon* \\ *Equipe d'accueil EA 1684, GPMA, Université de Bourgogne, 1 esplanade Erasme, 21000 Dijon, France \\ †Unité Mixte de Recherche 1129 FLAVIC AgroSup Dijon-INRA-UB, 17 rue Sully, 21065 Dijon, France \\ fLaboratoire de Mathématiques Appliqués à l'Informatique et aux Statistiques, AgroSup Dijon, 26 boulevard Docteur Petitjean, 21079 Dijon, \\ France \\ §Equipe d'accueil EA581, EMMA, Université de Bourgogne, 1 esplanade Erasme, 21000 Dijon, France
}

\begin{abstract}
Milk oxidoreduction potential was modified using gases during the production of a model dairy product and its effect on gel setting was studied. Acidification by glucono- $\delta$-lactone was used to examine the physicochemistry of gelation and to avoid variations due to microorganisms sensitive to oxidoreduction potential. Four conditions of oxidoreduction potential were applied to milk: milk was gassed with air, nongassed, gassed with $\mathrm{N}_{2}$, or gassed with $\mathrm{N}_{2} \mathrm{H}_{2}$. The rheological properties and microstructure of these gels were determined using viscoelasticimetry, measurement of whey separation, and confocal laser scanning microscopy. It appeared that a reducing environment led to less-aggregated proteins within the matrix and consequently decreased whey separation significantly. The use of gas to modify oxidoreduction potential is a possible way to improve the quality of dairy products.
\end{abstract}

Key words: oxidoreduction potential, acid skim milk gel, gel structure, glucono- $\delta$-lactone

\section{INTRODUCTION}

Yogurt is one of the most popular fermented dairy products. The manufacture of yogurt has previously been reviewed by different authors (Robinson and Tamine, 1993; Mulvihill and Grufferty, 1995; Tamine and Marshall, 1997). The production of yogurt is based on lactic acid fermentation, which leads to the acidification and thus to the gel-setting of milk. According to the French standard (Codex Alimentarius, 2003), yogurt is manufactured by using a mixed culture of Lactobacillus delbrueckii ssp. bulgaricus and Streptococcus thermophilus.

Received June 16, 2009.

Accepted September 1, 2009.

${ }^{1}$ Corresponding author: n.cayot@agrosupdijon.fr
The oxidoreduction potential (Eh) of a solution corresponds to the overall availability of electrons in the solution. Electrochemical measurement of Eh is not new but has attracted little attention as a control parameter of fermentation processes because of the sensitivity of its measurement. However, Eh is indirectly taken into account in the industrial environment through oxygen; the inhibitory effect of oxygen on lactic acid bacteria is well known. Indeed, oxygen modifies the growth of microorganisms and the formation of end products and so may contribute to the quality of fermented products (Dave and Shah, 1997; Rödel and Scheuer, 2000; van Dijk et al., 2000). Among fermented products, dairy products have recently been shown to be affected by Eh (Abraham et al., 2007; Cachon et al., 2007). In particular, Cachon et al. (2007) showed that the sensory properties of a fermented dairy product can be modified by using gases to change the Eh of milk.

These modifications may be the result of the effect of Eh on physicochemistry phenomena or on lactic acid bacteria, or on both. The aim of the present study was to determine to what extent chemical phenomena have an effect on the acid milk gelation under varying Eh conditions.

For this purpose, milk acidified using glucono- $\delta$-lactone (GDL) was chosen as a model gel to avoid variations caused by microorganisms sensitive to oxidoreduction potential. The hydrolysis of GDL into gluconic acid results in a reduction in $\mathrm{pH}$. Its $\mathrm{pKa}(3.60)$ is very similar to that of lactic acid $(3.79)$ at $25^{\circ} \mathrm{C}$, and GDL leads to the homogeneous acidification of the system. Indeed, in the dairy industry GDL is used to produce cottage cheese, feta cheese, and tofu because it gives excellent control and reproducibility of $\mathrm{pH}$ decrease and it can be added to milk at almost any temperature.

Several studies have reported the rheological properties of acid milk gels formed by GDL (Cobos et al., 1995; van Vliet and Keetels, 1995; Lucey et al., 1997a) or bacterial fermentation (Biliaderis et al., 1992; Rönnegard and Dejmek, 1993). Other authors have com- 
pared the properties of gels formed by both methods (van Marle and Zoon, 1995; Lucey et al., 1998a). Gels acidified by GDL were different from those acidified with bacterial cultures: $\mathrm{pH}$ decreased more rapidly, whey separation was greater, and the storage (elastic) modulus $\left(\mathbf{G}^{\prime}\right)$ values of gels were higher than those of bacterial gels. Gels made with bacterial cultures also appeared to have thicker strands and clusters of aggregated particles compared with GDL-induced gels (Lucey et al., 1998a).

The objective of this study was to determine the effects of Eh on model acidified skim milk gels obtained with GDL and prepared under different gaseous conditions. Air is an oxidizing medium; nitrogen, which is a neutral gas, can be used to remove oxygen from milk (but Eh remains positive); and hydrogen provides a reducing Eh (below 0). The effect of gas bubbling on gel structure was also studied. During the acidification step, $\mathrm{pH}$ and Eh profiles and rheology were tracked. Gel structure was then observed during storage for up to $28 \mathrm{~d}$.

\section{MATERIALS AND METHODS}

\section{Materials}

Ultra-high temperature organic skim milk (Lactel, Laval, France) was purchased at a local market and stored at room temperature. For each batch of milk, total nitrogen content was estimated by using the Kjeldahl procedure (Rowland, 1938) and was found to be constant for all milk samples $(5.45 \mathrm{~g} / \mathrm{L} \pm 0.15)$, which corresponded (using a coefficient of conversion $\mathrm{K}=6.36$ and 5 to $10 \%$ nonprotein nitrogen, $15 \%$ maximum), to 31 to $33 \mathrm{~g} / \mathrm{L}$ of protein. Low-heat skim milk powder was supplied by Eurosérum (St. Martin Belle Roche, France). This powder was stored at $4^{\circ} \mathrm{C}$ in sealed plastic bags under a nitrogen atmosphere to limit oxidation. In all experiments, milk powder from the same batch was added $[2 \%(\mathrm{wt} / \mathrm{vol})]$ to fortify the liquid skim milk (approximately $7 \mathrm{~g} / \mathrm{L}$ of protein added). The GDL and sodium azide $\left(\mathrm{NaN}_{3}\right)$ were supplied by Sigma (St. Quentin Fallavier, France).

\section{Acidification of Milk}

The fortified milk was stirred for $4 \mathrm{~h}$ after addition of the skim milk powder and heated to $45^{\circ} \mathrm{C}$. The fortified milk was then processed under 4 different gaseous conditions. Three different Eh conditions - milk was gassed with air, gassed with $\mathrm{N}_{2}$, or gassed with nitrogen plus $4 \%$ (vol/vol) hydrogen $\left(\mathrm{N}_{2} \mathrm{H}_{2}\right)$-were obtained by gas bubbling during stirring at a gas flow of $20 \mathrm{~mL} / \mathrm{min}$. For $\mathrm{N}_{2}$ and $\mathrm{N}_{2} \mathrm{H}_{2}$ conditions, gas bubbling was done in an anaerobic chamber (Bactron I, Sheldon Manufacturing, Cornelius, OR). To check the effect of gas bubbling, some experiments were done under a fourth condition: nongassed milk (ambient oxidizing condition). After the bubbling procedure, $0.02 \%$ (wt/wt) of $\mathrm{NaN}_{3}$ was added to prevent bacterial growth and acidification was started by the addition of $1.3 \%$ (wt/wt) of GDL. When $\mathrm{pH}$ reached 4.6 , the gels were cooled to $4^{\circ} \mathrm{C}$ in a bath of ice water during $1 \mathrm{~h}$ and stored at this temperature.

\section{Eh and $\mathrm{pH}$ Measurements}

To measure $\mathrm{pH}$, a combined autoclavable $\mathrm{pH}$ electrode (Mettler-Toledo SARL, Paris, France) was used. The $\mathrm{pH}$ electrode was calibrated using $\mathrm{pH} 7$ and $\mathrm{pH} 4$ calibration buffers and was cleaned with a pepsin/ $\mathrm{HCl}$ solution (Poly Labo, Paris, France) after each run.

Oxidoreduction potential was measured by combined autoclavable redox electrodes (Mettler-Toledo SARL, Paris, France). The electrodes had a ceramic diaphragm and a platinum band. Before each use, the redox electrodes were polished with fine alumina powder (aluminum oxide; VWR Prolabo, Lyon, France) to restore the platinum surface and were controlled in tap water. Three measurements in tap water were compared and were included in the confidence interval around their mean value (calculated at $20 \mathrm{mV}, 95 \%$ confidence level) to ensure correct measurement (Abraham et al., 2007). For $\mathrm{N}_{2}$ and $\mathrm{N}_{2} \mathrm{H}_{2}$ conditions, $\mathrm{pH}$ and Eh measurements were done in the Bactron I anaerobic chamber.

\section{Data Acquisition of $\mathrm{pH}$ and Eh Profiles}

The redox and $\mathrm{pH}$ electrodes and the temperature sensor were connected to an interface (ELIT multichannel pH meter/redox meter computer interface, Bioblock, Illkirch, France) that enabled real-time data acquisition on a computer. The $\mathrm{pH}$ and the measured redox potential $(\mathbf{E m} ; \mathrm{mV})$ values were followed simultaneously. The Em values were converted into Eh values according to the standard redox potential of the reference electrode (Er) using the equation

$$
\mathrm{Eh}=\mathrm{Em}+\mathrm{Er},
$$

where Eh is the redox potential related to the normal hydrogen electrode, Em is the redox potential measured, and Er is the redox potential of the reference electrode.

The Er differs as a function of temperature and the type of electrode. In our study, the redox electrode $(\mathrm{Pt}$ 4805-SC, Mettler-Toledo, Paris, France) had an Er of $192 \mathrm{mV}$ at $45^{\circ} \mathrm{C}$. Measured potential values were $\mathrm{pH}$ 
dependent. It was possible to overcome $\mathrm{pH}$ dependency by applying the Leistern and Mirna (1959) equation:

$$
\mathrm{Eh}_{7}=\mathrm{Eh}-[(7-\mathrm{pH}) \alpha]
$$

where $\mathbf{E h}_{\mathbf{7}}(\mathrm{mV})$ is the redox potential Eh at $\mathrm{pH} 7, \mathrm{Eh}$ is the redox potential related to the normal hydrogen electrode, and $\alpha(\mathrm{mV} / \mathrm{pH}$ unit) is the Nernst Eh- $\mathrm{pH}$ correlation factor. This factor must be determined experimentally (Jacob, 1970) by the measurement of Eh variation with $\mathrm{pH}$ using lactic acid or $\mathrm{NaOH}$. For the skim milk used in this study, we measured an Eh variation of $40 \mathrm{mV} / \mathrm{pH}$ units at $45^{\circ} \mathrm{C}$, which is in agreement with the results obtained by Cachon et al. (2002).

The $\mathrm{Eh}_{7}$ values were $+433 \mathrm{mV}( \pm 6 \mathrm{mV})$ in the milk gassed with air, $+405 \mathrm{mV}( \pm 22 \mathrm{mV})$ in the nongassed milk, $+283 \mathrm{mV}( \pm 13 \mathrm{mV})$ in the milk gassed with $\mathrm{N}_{2}$, and $-349 \mathrm{mV}( \pm 6 \mathrm{mV})$ in the milk gassed with $\mathrm{N}_{2} \mathrm{H}_{2}$.

\section{Rheological Properties}

Viscoelastic Properties and Gel Setting. Acid milk gels are viscoelastic and their viscoelastic properties can be determined by low-amplitude dynamic oscillation (Lucey et al., 1998a). During acidification of fortified milk, elastic $\left(G^{\prime}\right)$ and viscous $\left(\mathbf{G}^{\prime \prime}\right)$ moduli were followed as a function of time (until pH 4.6) on a controlled-stress rheometer SR5 (Rheometric Scientific, Piscataway, NJ) equipped with coaxial cylinders (cup diameter $=33 \mathrm{~mm}$, bob diameter $=31.5 \mathrm{~mm}$, bob length $=60 \mathrm{~mm}$ ). The cup and the bob of the rheometer were disinfected with ethanol (96\%), and 23 $\mathrm{mL}$ of the fortified milk was then transferred into the rheometer, which was preheated to $45^{\circ} \mathrm{C}$. If required, gas bubbling was done directly in the bob for $4 \mathrm{~h}$ at a gas flow of $20 \mathrm{~mL} / \mathrm{min}$ before the addition of GDL to the milk. Samples were covered with paraffin oil to prevent evaporation.

In the first step, oscillatory tests were carried out at $1 \%$ strain and $1 \mathrm{rad} \cdot \mathrm{s}^{-1}$ frequency (within the linear viscoelastic range) for $24 \mathrm{~h}$ at $45^{\circ} \mathrm{C}$. This was done 3 times for each experimental condition to follow complete gel setting.

Then, oscillatory tests were carried out at $1 \%$ strain and at a frequency of $1 \mathrm{rad} \cdot \mathrm{s}^{-1}$ with the following sequence: 1) a mechanical spectrum at $45^{\circ} \mathrm{C}$ for $10 \mathrm{~h}$ for GDL-induced gels; 2) measurements as a function of time (for $2 \mathrm{~h} 30 \mathrm{~min}$ ) upon cooling to $4^{\circ} \mathrm{C}$; and 3 ) a mechanical spectrum at $4^{\circ} \mathrm{C}$ for $2 \mathrm{~h}$. All experiments were done in triplicate. Only the evolution of $G^{\prime}$ and $\mathrm{G}^{\prime \prime}$ at $45^{\circ} \mathrm{C}$ during $24 \mathrm{~h}$ and the mechanical spectrum at $4^{\circ} \mathrm{C}$ during $2 \mathrm{~h}$ (plot recorded at the end of the $2 \mathrm{~h}$ ) are reported in the Results and Discussion.
Apparent Viscosity. A viscosimeter RM 180 (Mettler-Toledo, Greifensee, Switzerland) was used with the coaxial cylinders fixture (cup diameter $=32.54 \mathrm{~mm}$, bob diameter $=30 \mathrm{~mm}$, bob length $=45 \mathrm{~mm}$ ). The apparent viscosity $\eta(\mathrm{Pa} \cdot \mathrm{s})$, defined as the ratio of the shear stress $\tau(\mathrm{Pa})$ to the shear rate $\dot{\gamma}\left(\mathrm{s}^{-1}\right)$, was measured. After $1 \mathrm{~d}$ of storage, $25 \mathrm{~mL}$ of each gel was introduced into the cup of the viscosimeter. For each sample, an up-down shear scan from 10 to $1,000 \mathrm{~s}^{-1}$ was applied at $4^{\circ} \mathrm{C}$. All experiments were done in triplicate. The apparent viscosity was recorded at $500 \mathrm{~s}^{-1}$ during the up cycle.

\section{Measurement of Whey Separation}

Gels were made in 25-mL Schott flasks with $25 \mathrm{~mL}$ of fortified milk. After $24 \mathrm{~h}$ at $4^{\circ} \mathrm{C}$, whey was collected with a syringe from the top or around the sides of the flasks and weighed. The extent of whey separation was expressed as a percentage of the total milk volume. Four flasks were used for each measurement. Whey separation was measured after $1,7,14,21$, and $28 \mathrm{~d}$ of storage at $4^{\circ} \mathrm{C}$.

\section{Confocal Laser Scanning Microscopy}

The microstructure of the acid milk gels was observed by confocal laser scanning microscopy (CLSM) as done by Lucey et al. (1997b, 1998b). The fluorescent protein dye Fast Green FCF (Merck, Darmstadt, Germany) was used for noncovalent staining of the protein matrix. Fast Green was dissolved in demineralized water and several drops were added to $25 \mathrm{~mL}$ of fortified milk. After 5 min of stirring, $\mathrm{NaN}_{3}$ and GDL were added and a few drops of the mixture were transferred to a glass slide and a coverslip was placed over the sample. The object glass was then placed in a petri dish and kept in a temperature-controlled room at $45^{\circ} \mathrm{C}$ and under suitable gaseous conditions for approximately $16 \mathrm{~h}$. The gels were examined under a confocal microscope (Nikon Eclipse TE 2000 E, Tokyo, Japan) with a $100 \times$ oil immersion objective (numerical aperture $=1.4$ ). The CLSM had an air cooled He/Ar laser that was used with an excitation wavelength of $568 \mathrm{~nm}$. All experiments were done in triplicate. Many optical sections were viewed; 6 representative optical sections were selected for each system for further analyses.

\section{Image Analysis}

Concepts of Image Processing. A color image is an $\mathrm{N} \times \mathrm{M} \times \mathrm{P}$ matrix, where $\mathrm{N}$ is the width of the image, $\mathrm{M}$ is the height, and $\mathrm{P}$ is the colorimetric 
information (number of color bands). A pixel is the elementary element of an image. It corresponds to a single point $\mathrm{P}_{\mathrm{ij}}$ with its colorimetric information; $\mathrm{i}$ and $\mathrm{j}$ are the coordinates of the pixel in the image. For a color image, $\mathrm{P}=3$ and the 3 bands are respectively red, green, and blue; for a binary image, $\mathrm{P}=1$ and pixels can be only on or off (white or black/1 or 0 ).

Preprocessing. The original CLSM images we obtained were gray-level images. Each image consisted of a $20-\mu \mathrm{m}$ scale image and had a resolution of $512 \times 512$ pixels, which is well suited to the scale of our biological application and time processing. Before image processing, the CLSM images were converted from gray levels to binary, where 1's represent protein zones and 0's represent void zones.

Features of the CLSM Images. The CLSM images obtained for these experiments showed that there was a subjective difference in the aggregation of proteins. To determine whether Eh conditions provided significant differences, several kinds of features were extracted. Two features were retained from Gustafson (1998) and McGarigal and Marks (1995): the black:white ratio and aggregation.

To estimate whether the pore:protein ratio was constant for the different Eh conditions, a black:white ratio was extracted. This ratio is expressed as

$$
B / W=\frac{\text { number of black pixels }}{\text { number of white pixels }+1},
$$

where $B$ is black (pores) and $W$ is white (proteins).

Aggregation corresponds to the number of adjacent links involving the corresponding class, divided by the maximum possible number of adjacent links involving the corresponding class, which is achieved when the class is maximally clumped into a single, compact patch:

$$
\begin{aligned}
& \text { Aggregation }=\left(\frac{g_{i i}}{\max g_{i i}}\right) \\
& \max -g_{i i}= \begin{cases}2 n(n-1) ; & m=0 \\
2 n(n-1)+2 m-1 ; & m \leq n \\
2 n(n-1)+2 m-2 ; & m>n\end{cases} \\
& m=a_{i}-n^{2},
\end{aligned}
$$

where $g_{i i}$ is the number of shared edges for pixels of the studied class, $\max g_{i i}$ is the maximum number of shared edges that pixels of the studied class could have, $a_{i}$ is the area of studied zone, and $n$ is the square root of the maximum $n \times n$ area included in $a_{i}$. This parameter represents how the proteins aggregate within the gel. The more the proteins aggregated in a restricted number of compact blocks, the greater the aggregation percentage.

\section{Statistical Analysis}

Statistical analyses of results were made with StatBox software (version 6.5, Grimmer Logiciels, Issy les Moulineaux, France). An ANOVA test was used to compare averages of whey separation percentages and to compare features of the CLSM images. Differences were considered significant for the risk $\alpha \leq 0.05$.

\section{RESULTS AND DISCUSSION}

\section{Evolution of $\mathrm{pH}$ and Redox Potential}

The acidification profiles of milk acidified with GDL under the different gaseous conditions are presented in Figure 1A; GDL was rapidly hydrolyzed to gluconic acid, resulting in a rapid initial reduction in $\mathrm{pH}$ as previously reported by Lucey et al. (1998a). After approximately $30 \mathrm{~min}$ of rapid decrease, $\mathrm{pH}$ decreased more slowly and finally reached the target $\mathrm{pH}$. This was in agreement with the results of Amice-Quemeneur et al. (1995). The final $\mathrm{pH}$ (4.6) was a function of the amount $(1.3 \%)$ of GDL added to milk. The $\mathrm{pH}$ versus incubation time profile was almost the same regardless of the gaseous condition applied to the milk, and the final $\mathrm{pH}$ of 4.6 was reached after approximately $3.5 \mathrm{~h}$. Moreover, based on $\mathrm{pH}$ measurements, it was shown that the acidification kinetics of milk with GDL was a kinetic of order 1 regardless of the Eh condition.

The evolutions of $\mathrm{Eh}_{7}$ measured in milk acidified with GDL as a function of time are presented in Figure 1B. The effects of 4 different Eh were investigated: $+433 \mathrm{mV}$ (milk gassed with air), $+405 \mathrm{mV}$ (ungassed milk), +283 $\mathrm{mV}$ (milk gassed with $\mathrm{N}_{2}$ ), and $-349 \mathrm{mV}$ (milk gassed with $\mathrm{N}_{2} \mathrm{H}_{2}$ ). For all Eh conditions except for $\mathrm{N}_{2} \mathrm{H}_{2}$, Eh remained constant during acidification. For GDL gels made under $\mathrm{N}_{2} \mathrm{H}_{2}$ conditions, Eh increased gradually to a plateau value of $-100 \mathrm{mV}$, which was reached after 2 h. The increase of $\mathrm{Eh}$ in the $\mathrm{N}_{2} \mathrm{H}_{2}$ condition was also observed by Giroux et al. (2008) in dairy beverages during $6 \mathrm{~d}$ of storage and by Schreyer et al. (2008) in pasteurized skim milk during $16 \mathrm{~d}$ of storage, but the phenomenon they observed was slower than what we measured. It is possible that hydrogen interacts with the medium. For example, hydrogen may interact in oxidoreduction reactions with protein, especially with thiol-disulfide residue, which would explain the increase in Eh. In fact, the sulfhydryl group and disulfide constitute a redox couple (Freedman and Corwin, 1949). The reduction of disulfide bridges of protein caused by 


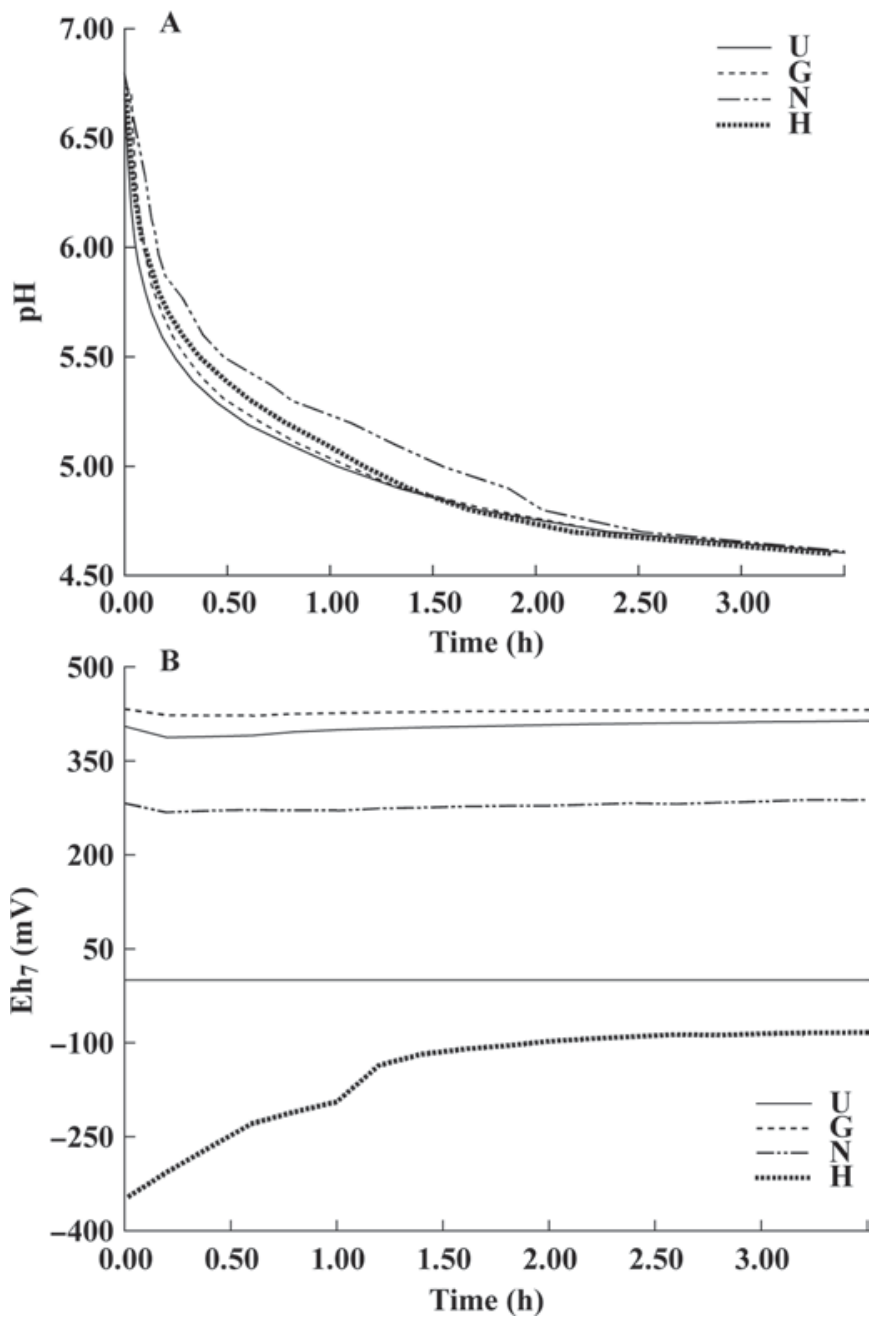

Figure 1. Evolution of (A) $\mathrm{pH}$ and (B) oxidoreduction potential $\left(\mathrm{Eh}_{7}\right)$ during the acidification of milk by glucono- $\delta$-lactone (GDL). Different gaseous treatments were applied to milk: ungassed (U), gassed with air $(\mathrm{G})$, gassed with $\mathrm{N}_{2}(\mathrm{~N})$, or gassed with $\mathrm{N}_{2} \mathrm{H}_{2}(\mathrm{H})$. Values are means from 3 experiments.

cystyl residue of $\beta$-lactoglobulin (2 per mole of protein), $\alpha$-lactalbumin (4 per mole of protein), BSA (18 per mole of protein), or polymerized $\alpha_{\mathrm{S} 2}$-casein (2 to 7 per mole of protein) on the surface of the casein micelle could explain the evolution of the potential after bubbling with hydrogen gas. No $\mathrm{pH}$ change was observed because of the very strong buffer capacity of caseins.

\section{Rheological Properties}

The rheological properties of the acidified milk were characterized at $45^{\circ} \mathrm{C}$ just after the addition of GDL and during the first $24 \mathrm{~h}$. Whey separation took place in the shearing tool of the rheometer and thus wall slip might have occurred. Only experiments with no wall slip were kept for further analysis. The curve presented in Figure 2A was obtained for milk acidified under the $\mathrm{N}_{2} \mathrm{H}_{2}$ condition and was a typical example of the evolution as a function of time of $\mathrm{G}^{\prime}$ and $\mathrm{G}^{\prime \prime}$ for milk acidified by GDL. The results showed that $\mathrm{G}^{\prime}$ and $\mathrm{G}^{\prime \prime}$ started to increase just after the addition of GDL, and initially increased steeply. With time, the increase in $\mathrm{G}^{\prime}$ and $G^{\prime \prime}$ leveled off and a plateau value was reached at 19 h. Throughout the measurements, G' was substantially higher than $G^{\prime \prime}$, which is in agreement with the literature (Lucey and Singh, 1997).

A typical mechanical spectrum of GDL-acidified milk obtained under the $\mathrm{N}_{2} \mathrm{H}_{2}$ condition is shown in Figure $2 \mathrm{~B}$. The mechanical spectrum corresponds to variations in $\mathrm{G}^{\prime}$ and $\mathrm{G}^{\prime \prime}$ as a function of frequency. All acidified milk gels exhibited solid-like behavior as in Figure 2B, with $\mathrm{G}^{\prime}>\mathrm{G}^{\prime \prime}$ and $\mathrm{G}^{\prime}$ stable at low frequencies.

The rheological properties (viscoelasticity and flow behavior) of each gel were characterized at $\mathrm{pH}=4.6$, $4^{\circ} \mathrm{C}$, and $24 \mathrm{~h}$ after GDL addition. Table 1 shows $\mathrm{G}^{\prime}$ at $1 \mathrm{rad} \cdot \mathrm{s}^{-1}$ and the apparent viscosity at $500 \mathrm{~s}^{-1}$ under the different Eh conditions.

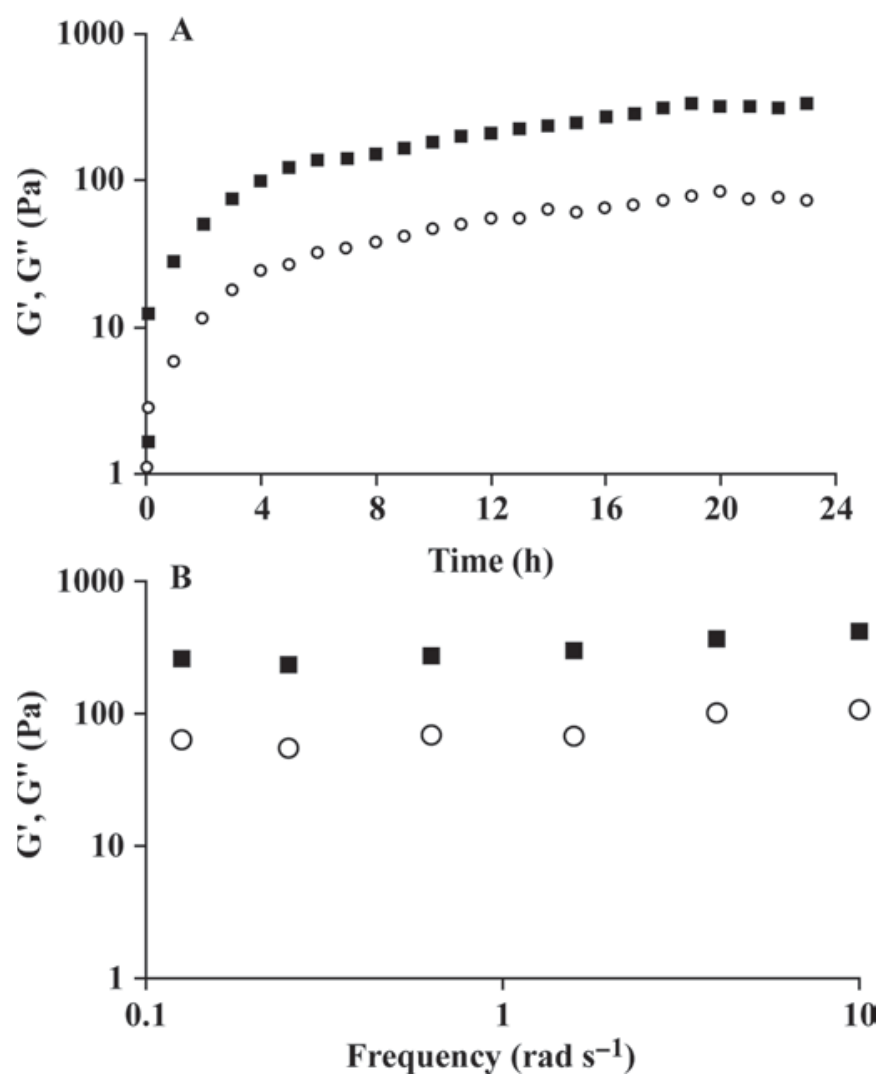

Figure 2. (A) Storage modulus $\left(\mathrm{G}^{\prime} ; \mathbf{\square}\right)$ and loss modulus $\left(\mathrm{G}^{\prime \prime}\right.$; $\bigcirc)$ for acid milk gels acidified by glucono- $\delta$-lactone (GDL) under $\mathrm{N}_{2} \mathrm{H}_{2}$ conditions. (B) Mechanical spectrum of $\mathrm{G}^{\prime}(\mathbf{\square})$ and $\mathrm{G}^{\prime \prime}(\mathrm{O})$ for acid milk gels acidified by GDL under $\mathrm{N}_{2} \mathrm{H}_{2}$ conditions. 


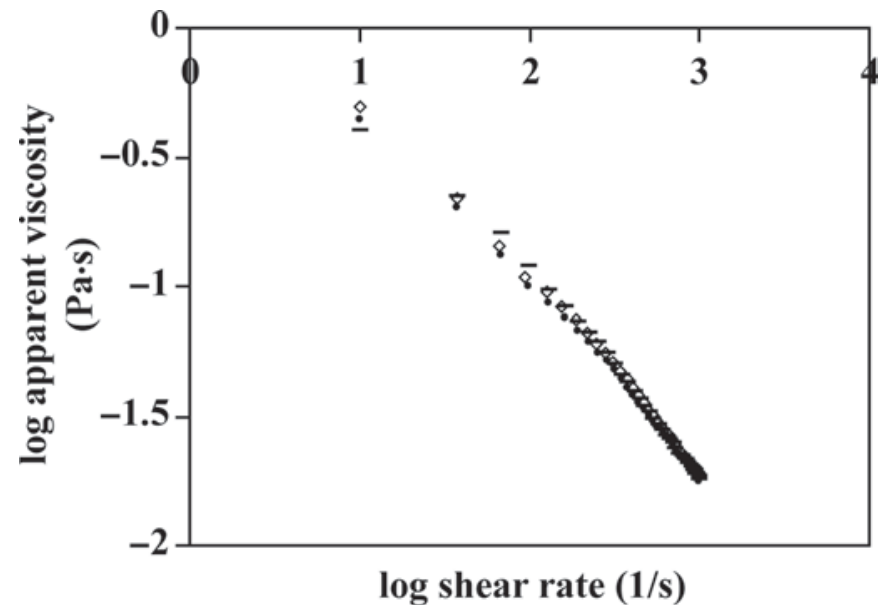

Figure 3. Flow curves (3 replications) for acid milk gels acidified by glucono- $\delta$-lactone (GDL) under $\mathrm{N}_{2} \mathrm{H}_{2}$ conditions. Values at $500 \mathrm{~s}^{-1}$ were recorded to compare apparent viscosity in the different gels.

The $\mathrm{G}^{\prime}$ modulus ranged from 35 to $959 \mathrm{~Pa}$. The stiffest gel was obtained from ungassed milk. The values obtained for gassed milk were lower and the lowest value was obtained for bubbled air. It can be concluded that bubbling decreases gel stiffness. Additionally, oxidizing conditions lead to gels that are significantly less firm.

An example of a flow curve obtained after the breakup of the gels, typical of a shear-thinning, is shown in Figure 3. Apparent viscosity values were extracted from this type of curve and ranged from 0.032 to 0.039 $\mathrm{Pa} \cdot \mathrm{s}$. Here again, the highest value was obtained for air. Values obtained for bubbled air and bubbled $\mathrm{N}_{2} \mathrm{H}_{2}$ were similar and significantly lower than those obtained for bubbled $\mathrm{N}_{2}$. We can conclude that viscosity was affected by bubbling. The type of gas used for bubbling had a significant influence but no clear tendency can be taken from these results concerning the influence of an oxidizing or a reducing environment.

\section{Whey Separation}

Mean values of whey separation were calculated for the $28 \mathrm{~d}$ of storage of the various gaseous conditions applied to milk; values are presented in Table 1. Whey separation was produced from the very first day of storage and the volume of whey separation produced was almost constant during the $28 \mathrm{~d}$ of storage; this was observed for each gaseous condition. For gels made under air conditions, the whey separation produced (4.74 $\mathrm{g} / 100 \mathrm{~g}$ of GDL gels) was lower than what is reported in the literature: $18.48 \%$ of GDL gels in the work of Lucey et al. (1998a) and 10\% of gels in the study of Fiszman et al. (1999). Nevertheless, in the method used to collect whey separation in the study of Lucey et al.

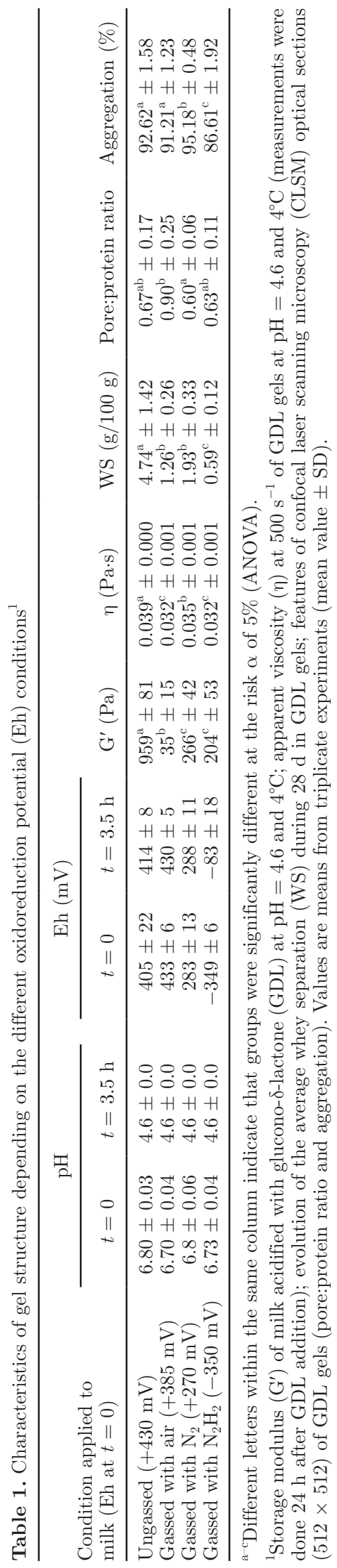

Journal of Dairy Science Vol. 92 No. 12, 2009 


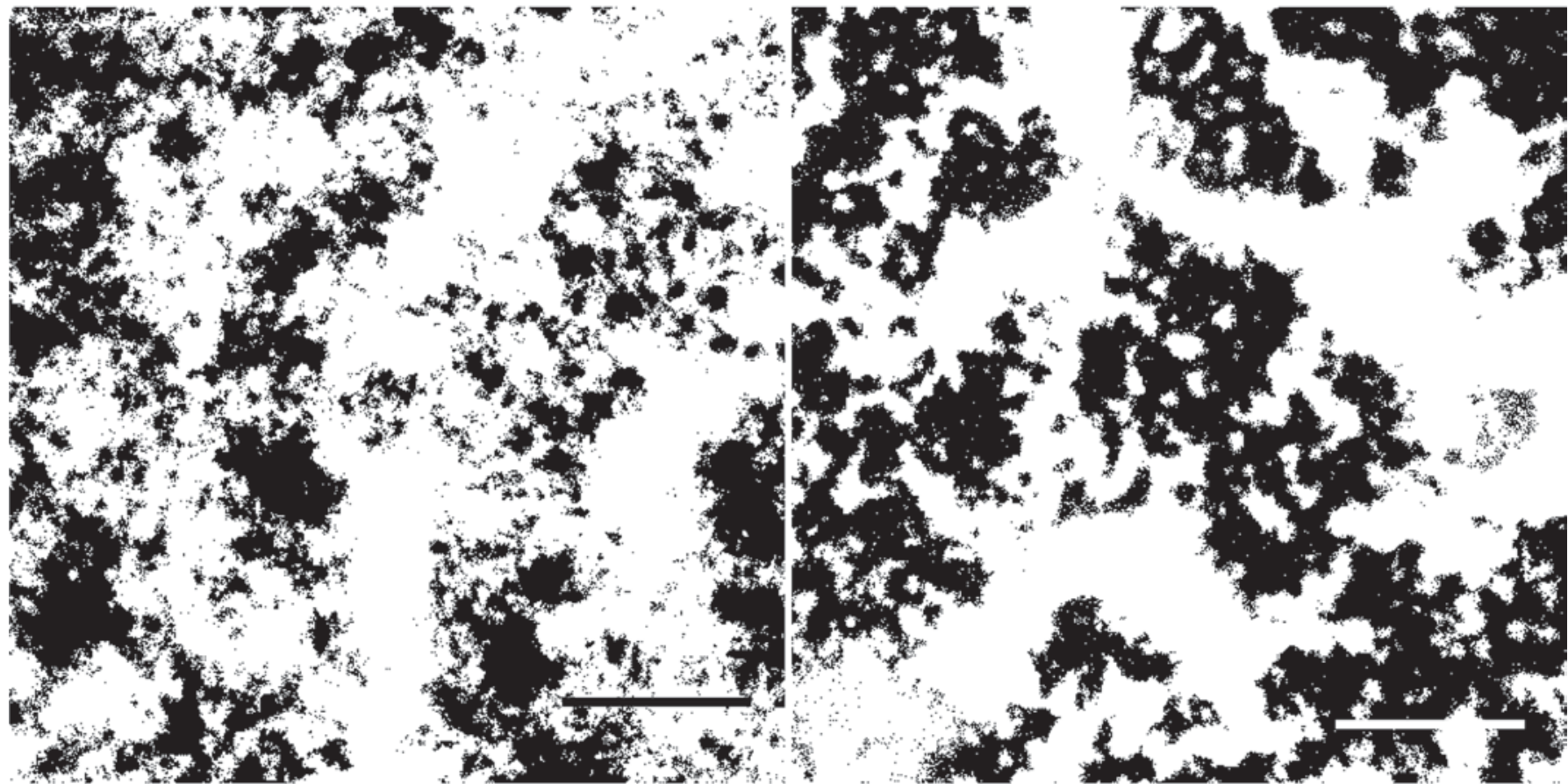

C

D

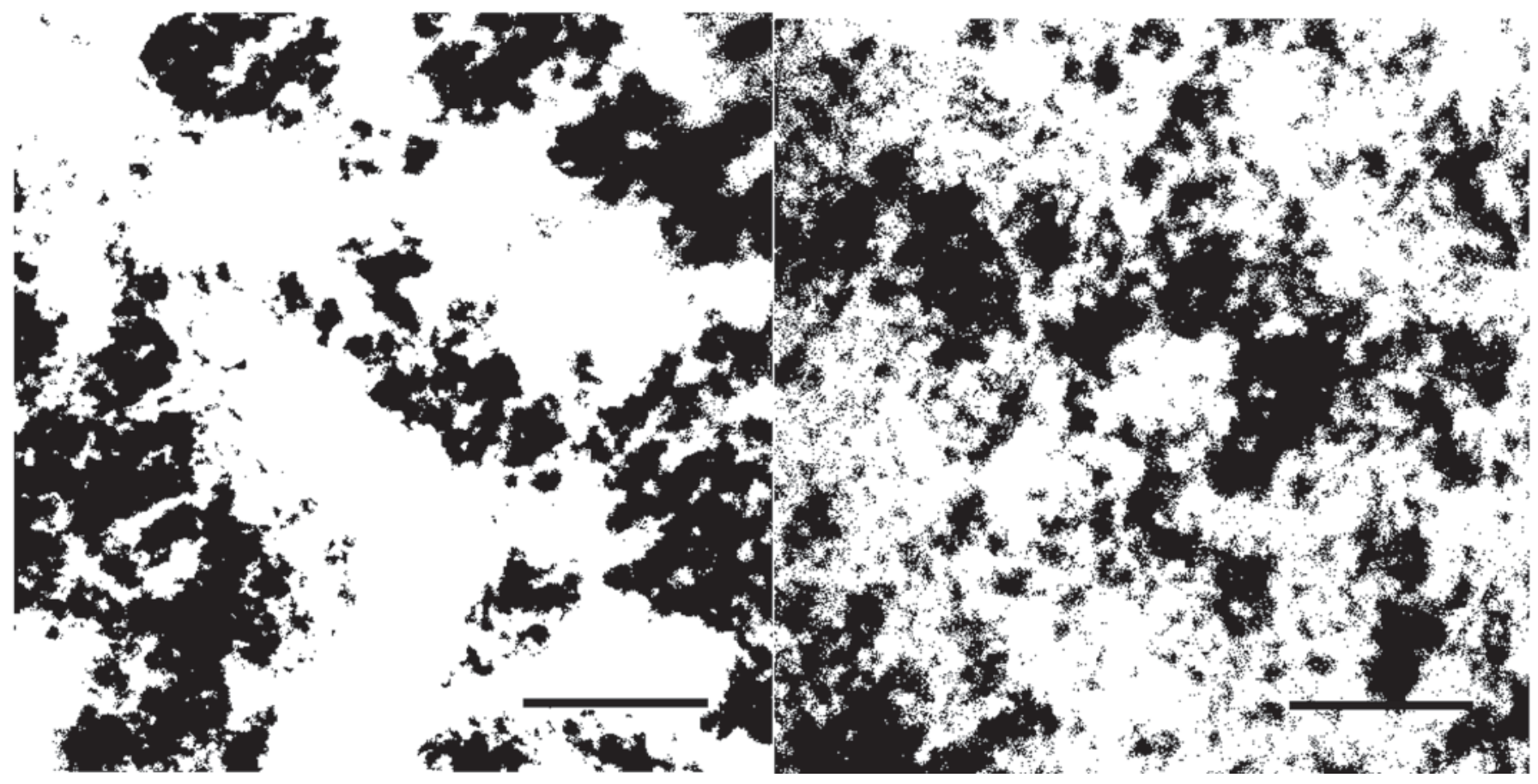

Figure 4. Confocal laser scanning micrographs $(512 \times 512)$ of acid milk gels acidified by glucono- $\delta$-lactone. Different gaseous treatments were applied to milk: (A) ungassed, (B) gassed with air, (C) gassed with $\mathrm{N}_{2}$, or (D) gassed with $\mathrm{N}_{2} \mathrm{H}_{2}$. The protein matrix appears white, whereas pores appear dark. Scale bar $=20 \mu \mathrm{m}$.

(1998a), the gels were removed from their flasks and thus whey separation could have been overestimated. Whey separation measured for GDL gels made under bubbled gas conditions $(1.26 \mathrm{~g} / 100 \mathrm{~g}$ for bubbled air,
$1.93 \mathrm{~g} / 100 \mathrm{~g}$ for bubbled $\mathrm{N}_{2}$, and $1.93 \mathrm{~g} / 100 \mathrm{~g}$ for bubbled $\mathrm{N}_{2} \mathrm{H}_{2}$ ) were lower.

Whey separation was significantly lessened under the bubbled $\mathrm{N}_{2} \mathrm{H}_{2}$ condition. Setting the Eh of milk under 
reducing conditions (under $\mathrm{N}_{2} \mathrm{H}_{2}$ ) could be a way to significantly diminish the phenomenon of whey separation.

\section{Structural Properties}

Representative CLSM of acid milk gels made under different gaseous conditions are shown in Figure 4. Regardless of the conditions of GDL gel production, the gel network appeared branched and had extensive apparent interconnectivity of aggregates. The network has pores or void spaces where the aqueous phase is confined. Image analysis was used to more precisely characterize the optical sections observed for each gel. As described in the Materials and Methods section, 2 features were used: a pore:protein ratio (i.e., a black:white ratio) and an aggregation feature indicating the size of the aggregates or lumps.

Mean values of these features are reported in Table 1. For all gels, the apparent protein volume fraction was higher than the space occupied by pores with pore:protein ratios $<1$. The highest value (i.e., the highest proportion of pores) was obtained for gels made under bubbled air conditions. For other conditions, the proportion of pores was similar and lower.

The aggregation feature was high (above 86\%) for each gel. Significant differences were found among the various gels: the lowest aggregation was found for gels treated with $\mathrm{N}_{2} \mathrm{H}_{2}$, the highest aggregation for gels treated with $\mathrm{N}_{2}$. Aggregation was found to be similar for both gassed- and ungassed-air conditions. A decrease in environmental Eh induced a modification in gel aggregation. In fact, a reducing Eh induced a lessaggregated gel; that is, the gel was less contracted and thus expelled less water. This is consistent with the low levels of whey separation observed for the gels made under reducing Eh.

The results of the present study showed that there were differences in the rheological and physical properties of acid skim milk gels made with GDL under different Eh conditions. The GDL-induced gels made under ungassed-air conditions appeared to be the stiffest gels (highest $\mathrm{G}^{\prime}$, low pore:protein ratio, high rate of whey separation). Gas bubbling, which is a mechanical treatment, had an effect on gel characteristics.

The relationships between rheological measurements and structure were not obvious. Additionally, the methods used to prepare the gels for the different analyses were not exactly the same. Nevertheless, it can be concluded that, among gels obtained from gassed milk, those made under $\mathrm{N}_{2} \mathrm{H}_{2}$ conditions were stiffer and exhibited less whey separation compared with those made under air conditions. It appeared that a reducing environment led to less-aggregated proteins within the matrix, which consequently decreased whey separation significantly.

\section{CONCLUSIONS}

In this study, the use of a model gel acidified by GDL showed that a modification of Eh by gases could induce some structural modifications of the milk gels. As stated in the introduction, GDL is commonly used in the dairy industry for cheese production. Such a modification of Eh by gas could be used to adjust some of the physicochemical properties of dairy products or to create new products.

\section{ACKNOWLEDGMENTS}

The work on confocal laser scanning microscopy was performed thanks to the Institut Fédératif de Recherche no. 92 imaging spectroscopy and rheology technical equipment and the financial support of the French government.

\section{REFERENCES}

Abraham, S., R. Cachon, B. Colas, G. Feron, and J. De Coninck. 2007. Eh and pH gradients in Camembert cheese during ripening: Measurements using microelectrodes and correlations with texture. Int. Dairy J. 17:954-960.

Amice-Quemeneur, N., J.-P. Haluk, J. Hardy, and T. P. Kratchenko. 1995. Influence of the acidification process on the colloidal stability of acidic milk drinks prepared from reconstitued nonfat dry milk. J. Dairy Sci. 78:2683-2690.

Biliaderis, C. G., M. M. Khan, and G. Blank. 1992. Rheological and sensory properties of yogurt from skim milk and ultrafiltered retentates. Int. Dairy J. 2:311-323.

Cachon, R., G. Feron, C. Delbeau, D. Ibarra, and H. Ledon, inventors. 2007. Process by which the sensory properties of a fermented dairy product are modified, and maturation thereof during the conservation of said product. L'Air Liquide, assignee. U.S. Pat. No. 0092605.

Cachon, R., S. Jeanson, M. Aldarf, and C. Divies. 2002. Characterisation of lactic starters based on acidification and reduction activities. Lait 82:281-288.

Cobos, A., D. S. Horne, and D. D. Muir. 1995. Rheological properties of acid milk gels. I. Effect of composition, process and acidification conditions on products from recombined milks. Milchwissenschaft 50:444-448.

Dave, R. I., and N. P. Shah. 1997. Effectiveness of ascorbic acid as an oxygen scavenger in improving viability of probiotic bacteria in yogurts made with commercial starter cultures. Int. Dairy J. $7: 435-443$.

Fiszman, S. M., M. A. Lluch, and A. Salvador. 1999. Effect of addition of gelatin on microstructure of acidic milk gels and yogurt and on their rheological properties. Int. Dairy J. 9:895-901.

Freedman, L. D., and A. H. Corwin. 1949. Oxidation-reduction potentials of thiol-disulfide systems. J. Biol. Chem. 181:601621.

Codex Alimentarius. 2003. French standard for fermented milks. Page 1 in Milk Products. Vol. 12. CODEX STAN 243. Codex Alimentarius, Paris, France.

Giroux, H. J., J. B. St-Amant, P. Fustier, J.-M. Chapuzet, and M. Britten. 2008. Effect of electroreduction and heat treatments on oxidative degradation of a dairy beverage enriched with polyunsaturated fatty acids. Food Res. Int. 41:145-153. 
Gustafson, E. J. 1998. Quantifying landscape spatial pattern: What is the state of the art? Ecosystems (N. Y., Print) 1:143-156.

Jacob, H. E. 1970. Redox potential. Pages 91-123 in Methods in Microbiology. J. R. Norris and D. W. Ribbons, ed. Academic Press, New York, NY.

Leistern, L., and A. Mirna. 1959. Das redoxpotential von pökelladen. Die Fleischwirtschaft 8:659-666.

Lucey, J. A., and H. Singh. 1997. Formation and physical properties of acid milk gels: A review. Food Res. Int. 30:529-542.

Lucey, J. A., M. Tamehana, H. Singh, and P. A. Munro. 1998a. A comparison of the formation, rheological properties and microstructure of acid skim milk gels made with a bacterial culture or glucono-[delta]-lactone. Food Res. Int. 31:147-155.

Lucey, J. A., C. T. Teo, P. A. Munro, and H. Singh. 1998b. Microstructure, permeability and appearance of acid gels made from heated skim milk. Food Hydrocoll. 12:159-165.

Lucey, J. A., T. van Vliet, K. Grolle, T. Geurts, and P. Walstra. 1997a. Properties of acid casein gels made by acidification with glucono-[delta]-lactone. 1. Rheological properties. Int. Dairy J. $7: 381-388$.

Lucey, J. A., T. van Vliet, K. Grolle, T. Geurts, and P. Walstra. 1997b. Properties of acid casein gels made by acidification with glucono[delta]-lactone. 2. Syneresis, permeability and microstructural properties. Int. Dairy J. 7:389-397.

McGarigal, K., and B. J. Marks. 1995. Fragstats: Spatial pattern analysis program for quantifying landscape structure. http:// umass.edu/landeco/research/fragstats/fragstats.html Accessed March 15, 2009

Mulvihill, D. M., and M. B. Grufferty. 1995. Effect of thermal processing on the coagulability of milk by acid. Pages 188-205 in Heat-Induced Changes in Milk. 2nd ed. P. F. Fox, ed. International Dairy Federation, Brussels, Belgium.
Robinson, R. K., and A. Y. Tamine. 1993. Manufacture of yogurt and other fermented milks. Pages 1-48 in Modern Dairy Technology. Vol. 2. Advances in Milk Products. 2nd ed. R. K. Robinson, ed. Elsevier, London, UK.

Rödel, W., and R. Scheuer. 2000. Redox potential of meat and meat products. III. Control of redox potential during meat processing: Effects of $\mathrm{pH}$-value, sodium nitrite, sodium ascorbate, sodium lactate and oxygen. Fleischwirtschaft Int. 40:78-84.

Rönnegard, E., and P. Dejmek. 1993. Development and breakdown of structure in yogurt studied by oscillatory rheological measurements. Lait 73:371-379.

Rowland, S. J. 1938. The determination of nitrogen distribution in milk. J. Dairy Res. 9:42-46.

Schreyer, A., M. Britten, J.-M. Chapuzet, J. Lessard, and L. Bazinet. 2008. Electrochemical modification of the redox potential of different milk products and its evolution during storage. Innov. Food Sci. Emerg. Technol. 9:255-264. doi:10.1016/j.ifset.2007.07.001.

Tamine, A. Y., and V. M. E. Marshall. 1997. Microbiology and technology of fermented milks. Pages 57-152 in Microbiology and Biochemistry of Cheese and Fermented Milk. 2nd ed. B. A. Law, ed. Blackie Academic and Professional, London, UK.

van Dijk, C., T. Ebbenhorst-Selles, H. Ruisch, T. Stolle-Smits, E. Schijvens, W. van Deelen, and C. Boeriu. 2000. Product and redox potential analysis of sauerkraut fermentation. J. Agric. Food Chem. 48:132-139.

van Marle, M. E., and P. Zoon. 1995. Permeability and rheological properties of microbially and chemically acidified skim-milk gels. Neth. Milk Dairy J. 49:47-65.

van Vliet, T., and C. J. A. M. Keetels. 1995. Effect of preheating of milk on the structure of acidified milk gels. Neth. Milk Dairy J. 49:27-35. 